\title{
Law, coercion, and the public health
}

\author{
Peter Old, Jonathan Montgomery
}

The tabloid headline "Arrested for having TB" is a forceful reminder of the unresolved ethical and legal issues surrounding the use of coercive measures to control infectious disease. The subject of the report was alleged to have committed a criminal offence by transmitting tuberculosis to his daughter. Additionally, there was the possibility of a manslaughter charge in connection with the death of a neighbour's child, but all charges were subsequently withdrawn. In this case the disease was tuberculosis, but a similar response might occur in relation to HIV infection. An alternative approach, invoking the Public Health (Control of Disease) Act 1984, has already been used to prevent a patient with AIDS who was "bleeding copiously" from discharging himself from hospital. ${ }^{2}$ The Public Health Act also provides powers of compulsory testing and removal to hospital under a magistrate's warrant.

Public health law raises a potentially irreconcilable conflict between public and private rights. The public right to protection was emphasised by the Conservative Family Campaign's Charter of Responsibilities for Citizens infected with HIV, while the infected person's rights to privacy and liberty were espoused in the UK Declaration of the Rights of People with HIV and AIDS. ${ }^{3}$ The latest story about tuberculosis illuminates these issues and presages the inevitable debate on the proper way to balance these rights. It raises a series of issues as to the role of the law in promoting public health: the appropriate use of the public health powers to police the victims of disease, the general duty of infected people to society, and their specific responsibilities to those they may infect.

The civil law is concerned with protecting individuals against the wrongs others may commit against them. It is invoked by the victim rather than the officers of society and aims to compensate them for the wrong they suffer rather than to punish the wrongdoer. Liability of this kind makes those with diseases responsible to their fellow citizens for safeguarding their good health. English law may allow a civil action against a person who infects another. Such cases are likely to be decided in "negligence": requiring the victim to show a sufficiently close connection with the infected person to make it just and reasonable that the law make the infected person responsible for the victim's welfare, that he or she failed to take such care as a reasonable person would have taken, and that the infection was caused by this carelessness. Judging what is just and reasonable is left to the courts, but raises important issues of ethics and social policy: how far are individuals to be made responsible for their neighbours' health?

Initially, this course of action seems attractive. If someone had been infected due to another's carelessness, they have a legitimate claim to be compensated. In addition, the threat of legal liability might discourage people from risking spreading disease. On the other hand, effective public health practice also depends on citizens taking responsibility for their own health. Imposing legal liability for infecting others implies that it is the person who transmits the disease, not the person who catches it, who is responsible. This might encourage people to see infectious disease as someone else's problem, a particularly dangerous possibility in relation to HIV. The balance of responsibility can be partially restored through the concept of contributory negligence, whereby "victims" who fail to take proper precautions can be held to be partially responsible for their own infection, and the amount of compensation payable will be reduced according to their share of the blame. But it is doubtful whether this would counteract the effect of making those already victims of a disease responsible for its control.

\section{Working with not against the infected}

To criminalise the transmission of disease is to impose on those who are infected a social duty to act responsibly to contain disease. Enforcing social responsibility through the threat of punishment is, however, probably counterproductive. It alienates those with disease and discourages them from seeking medical help. Effective disease control must depend primarily on working with those who are infected, not characterising them as the enemy. Desirable or not, invoking criminal liability for the transmission of disease requires navigating poorly charted legal waters. If a person knowingly transmits the disease to another he or she may commit a crime, but the prosecutor faces many difficulties. Even if it can be proved that the accused was the source of the infection, the technical requirements of the criminal offence may not be satisfied. With HIV infection, most methods of transmission involve consensual acts and the extent of the victim's own responsibility may be crucial. In the nineteenth century a man who knowingly infected his wife with gonorrhoea was found not guilty of assault because she was deemed to have consented to sexual intercourse even though she was unaware of his condition. ${ }^{4}$ This case is considered an unreliable guide to the modern law, but the true position remains obscure. $^{5}$

History suggests that the criminal law is unsuitable for dealing with sexually transmitted diseases. ${ }^{6}$ The redress offered by the civil law is largely compensatory, and although it may provide a remedy for individuals, it is unlikely to prove effective on the wider scale of protecting the public health. Both civil and criminal liability can be imposed only after the damage is done, and their contribution to preventing the spread of disease can be based only on any deterrent effects that can be claimed for them. Consequently, if society is to be protected an alternative approach is needed.

The statutory powers conferred on public health officials by the 1984 act and its associated regulations would seem the more appropriate vehicle for this proactive role. They can be exercised to prevent infection and limited to those cases where legal coercion is strictly necessary. Coercive measures will always be less effective than education and counselling, which maximise both the civil rights of the individual
University

Jonathan Montgomery lecturer

BMF 1992;304:891-2 
and the right of the general public to good health.? Nevertheless, in exceptional cases statutory intervention may be justified, but the present system may have failed to find the correct balance between the rights of the public and those of infected people.

The selective application of certain sections of the Public Health Act 1984 to HIV demonstrates a piecemeal approach to the development of the law. The act still contains many features which have endured from the great Public Health Act of 1875, based on robust utilitarian principles that were designed to deal with highly infectious diseases in emergency situations. It shows little concern for human rights or the principle of self determination. For example, compulsory examination may be justified if "it is in his (the infected person's) own interest or in the interest of his family or in the public interest."

Modern regimes of coercive medicine, such as the Mental Health Act 1983, contain a system of appeals and checks and balances to guard against potential abuse. Public health medicine has a strong tradition of utilitarian precepts and easily lapses into an uncritical, paternalistic philosophy. This anachronistic approach undermines the acceptability of the powers under the Public Health Act and also the National Assistance Acts. ${ }^{9}$ If powers of compulsion are to be maintained they must meet the standards of contemporary society.

The underlying assumption of modern legislation is that individuals are best placed to judge their own interests; the paternalism of the existing public health provisions is no longer appropriate. Only the threat to other members of society is usually thought to justify coercion, and where compulsion is necessary it must be exercised through fair procedures. The victim must be entitled to argue against the use of such powers, if possible before they are exercised, but if urgent action has been necessary the use of powers should be challengeable through appeal. Another example, taken from the Mental Health Act model, would be the dilution of the power of individual doctors by requiring consultation with other professionals.

The repeated consolidation of the old law withou major reform has resulted in a Public Health Act that is unable to adapt to its current role and is unfit for the new demands likely to be placed on it. In 1989 the Department of Health produced a thorough and welcome consultation document inviting views on possible changes to the law on infectious disease control in England and Wales. ${ }^{10}$ Given the contentious and non-consensual nature of the provisions contained in the current legislation and their consequences for the liberty of individuals, a comprehensive revision of the existing law is called for.

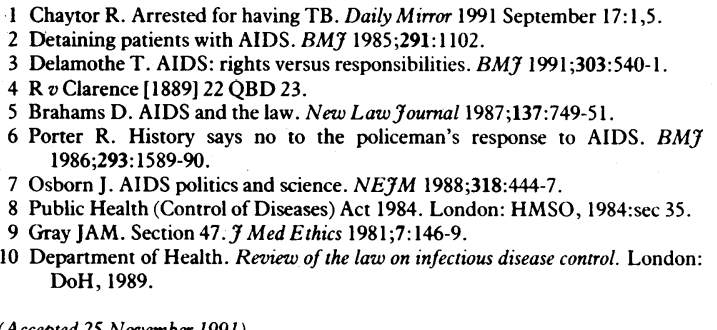

\title{
Public opinion, the NHS, and the media: changing patterns and perspectives
}

\author{
Ken Judge, Michael Solomon, David Miller, Greg Philo
}

The National Health Service has been at or close to the top of the political agenda since the summer of 1987 . One consequence has been a plethora of polls and surveys seeking to elicit the public's views about many different aspects of the health care system. Public opinion about the NHS is now thought to be a key political indicator, but its interpretation is fraught with difficulty.

Our first aim in this paper is to review trends in public opinion during the 1980s. We show how the reporting of the public's perceptions can be influenced by methodological issues such as the wording of questions and the context in which they are asked. Secondly, we present new data collected by the Office of Population Censuses and Surveys omnibus surveys and the University of Glasgow Media Group on behalf of the King's Fund. These data indicate how media coverage of the NHS in the last quarter of 1991 might have been related to changes in public opinion. Finally, we consider the possibility that public dissatisfaction with the NHS may have peaked in 1990.

BMF 1992;304:892-5

The latest figures on public attitudes indicate an increase in dissatisfaction with how the NHS is run. We do not attach any great significance to this, since, as we will argue, there are fluctuations in opinion which seem to relate to the changing media agenda and to the reflection by the media of political debate.

\section{Trends}

Two series of surveys over recent years have explored attitudes to the NHS.

\section{BRITISH SOCIAL ATTITUDES SURVEYS, 1983-90}

The British Social Attitudes survey regularly asks people about their levels of satisfaction with the NHS in general and with specific services in particular. Respondents are usually asked: "All in all, how satisfied or dissatisfied would you say you are with the way in which the National Health Service runs nowadays?" Table I shows that between 1983 and 1990 the proportion reporting dissatisfaction increased from a quarter to almost a half.

The general question about the NHS is usually followed by more specific questions concerning satisfaction with particular aspects of the health service. Respondents are asked: "From your own experience, or from what you have heard, please say how satisfied or dissatisfied you are with the way in which each of these parts of the National Health Service runs nowadays."

Table II shows that most dissatisfaction was expressed in relation to hospitals. While relatively low levels of dissatisfaction with other areas of the health

Numbers are percentages of people $\dagger$

\begin{tabular}{lcccccc}
\hline Response & $\begin{array}{c}1983 \\
(\mathrm{n}=1761)\end{array}$ & $\begin{array}{c}1984 \\
(\mathrm{n}=1675)\end{array}$ & $\begin{array}{c}1986 \\
(\mathrm{n}=3100)\end{array}$ & $\begin{array}{c}1987 \\
(\mathrm{n}=2847)\end{array}$ & $\begin{array}{c}1989 \\
(\mathrm{n}=3029)\end{array}$ & $\begin{array}{c}1990 \\
(\mathrm{n}=2797)\end{array}$ \\
\hline Satisfied (very or quite) & 55 & 51 & 40 & 41 & 36 & 37 \\
Neither & 20 & 19 & 19 & 20 & 18 & 15 \\
Dissatisfied (very or quite) & 25 & 30 & 39 & 39 & 46 & 47 \\
\hline
\end{tabular}

Source: British. Social Attitudes Surveys.

$\star$ The question was not asked in the 1985 survey; there was no survey in 1988 .

tThe percentages do not total 100 due to rounding up or down. 